\title{
ESTUDOS DE LÍNGUA JAPONESA ACADÊMICA: RETRATOS A PARTIR DO AKADEMIKKU JAPANÎZU JÂNARU (2009-2013)
}

Rodrigo Moura Lima de Aragão ${ }^{1},{ }^{2}$

Resumo: Objetivou-se retratar o estado atual da produção acadêmica sobre a língua japonesa acadêmica. Para tanto, foram analisados 28 textos publicados entre 2009 e 2013 no periódico japonês Akademikku Japanîzu Jânaru. Com insumos provenientes da administração (BERTERO; KEINERT, 1994; e outros), examinaram-se temas, percursos investigativos, aportes teóricos, referenciais metodológicos e fontes dos textos. Como resultado, delinearam-se cinco grupos temáticos próprios ao domínio dos estudos de japonês acadêmico: redação em língua japonesa, ensino-aprendizagem de língua japonesa, compreensão e expressão oral em japonês, citações e outros aspectos do texto japonês, outros assuntos. Temas, métodos, aportes teóricos, referenciais metodológicos e fontes identificados nos cinco grupos são variados, o que evidencia os estudos de língua japonesa acadêmica como um campo de investigação em fase de instituição.

Palavras-chave: Japonês acadêmico; Japonês para fins acadêmicos; Japonês para fins específicos; língua japonesa; estado da arte.

Abstract: The aim of this study was to describe the current state of research on academic Japanese. In order to do this, 28 texts published between 2009 and 2013 in the Japanese journal Akademikku Japanîzu Jânaru were analyzed. Using as input studies of management (BERTERO; KEINERT, 1994; among others), themes, methods, theoretical bases, methodological foundations, and

1. Professor de comunicação e metodologia científica na Faculdade de Tecnologia de Itaquera Professor Miguel Reale (FATEC Itaquera), São Paulo, SP, Brasil; mestrando em Língua, Literatura e Cultura Japonesa na Universidade de São Paulo (USP), São Paulo, SP, Brasil; aragao_rodrigo@yahoo.com.br.

2. O autor agradece ao parecerista anônimo da Revista Estudos Japoneses, pelas valiosas observações que permitiram o aprimoramento deste texto, e a Tomomi Aragão, pela preciosa assistência na revisão da romanização de dados escritos em língua japonesa (sobretudo no que diz respeito a nomes próprios japoneses). 
sources within the texts were examined. As a result, five thematic groups concerning the academic Japanese language have been observed: Japanese writing, teaching and learning of Japanese, oral comprehension and expression in Japanese, citations and other aspects of the Japanese text, and other themes. The subjects, methods, theoretical bases, methodological foundations, and sources found in the five groups are diverse. Such variety suggests that research on academic Japanese is still an emerging field.

Keywords: Academic Japanese; Japanese for academic purposes; Japanese for specific purposes; Japanese language; state of the art.

\section{Introdução}

Um papel de mais destaque tem sido atribuído à faceta acadêmica do japonês. A instituição do Nihon Ryûgaku Shiken, em 2002, e sua continuidade com número relativamente regular de participantes até hoje são indicativos disso, uma vez que a língua japonesa acadêmica constitui item central da prova, que se destina à admissão de estudantes estrangeiros em universidades japonesas. ${ }^{3}$ Além disso, o fato de que muitas instituições de ensino superior japonesas oferecem atualmente cursos e disciplinas que tratam de temas relacionados ao japonês acadêmico - como a estrutura e a linguagem de textos universitários japoneses e expressões próprias às apresentações orais acadêmicas em língua japonesa corrobora a posição de proeminência para a qual a língua japonesa acadêmica foi movida. ${ }^{4}$

A projeção do japonês acadêmico pode ser detectada ainda no que diz respeito à pesquisa de língua japonesa. A fundação, em 2004, do Akademikku Japanîzu Gurûpu, associação que reúne professores e pesquisadores que lidam com o japonês acadêmico, é um sinal disso. Ademais, a criação por essa associação, anos mais tarde, em 2009, do Akademikku Japanîzu Jânaru, periódico destinado à publicação de trabalhos escritos relacionados ao japonês acadêmico, também evidencia tal projeção.

Uma vez que os membros da comunidade brasileira de estudos japoneses, seja pela leitura, pela escrita ou pela comunicação oral, usualmente têm de manusear ou enfrentar a língua japonesa acadêmica, não parece razoável que essa comunidade se mantenha alheia ao movimento delineado. Considera-se importante que se empreendam esforços no sentido de incorporar de modo mais expressivo o japonês acadêmico a atividades de ensino. Ainda, consideram-se fundamentais iniciativas no sentido de produzir conhecimento relacionado à língua japonesa acadêmica. Por onde, entretanto, começar tal empresa investigativa?

Alguns insumos para formular respostas a essa pergunta podem ser encontrados no

3. Segundo dados da Japan Student Services Organization (2014), entidade responsável pelo exame, a primeira edição da prova contou com 7.655 participantes e, desde então, entre 13 e 24 mil pessoas têm prestado o exame todos os anos.

4. Como exemplo, pode ser citada a Universidade de Hokkaidô, que tem disciplinas dessa natureza tanto em seus currículos de graduação como em programas voltados a estudantes estrangeiros - informações adicionais podem ser encontradas no sistema de busca de disciplinas da instituição (HOKKAIDÔ DAIGAKU, 2014) e na página de seu centro de estudantes estrangeiros (HOKKAIDÔ DAIGAKU RYÛGAKUSEI SENTÂ, 2014). 
texto de Horii (2009), que sintetiza as ações do Akademikku Japanîzu Gurûpu desde sua fundação. A autora compila os temas e as atividades de 17 reuniões científicas realizadas pela associação, discute os resultados dos esforços do grupo e aponta questões a serem enfrentadas no campo dos estudos de língua japonesa acadêmica. Mesmo assim, avalia-se como indispensável a reunião de mais elementos, a fim de que se tornem mais claras as frentes que estão tomando forma no domínio da pesquisa de japonês acadêmico.

Este trabalho flui nesse sentido. Retratos do que vem sendo produzido até o momento sobre a língua japonesa acadêmica são esboçados a partir da análise de textos publicados no Akademikku Japanîzu Jânaru. De modo mais preciso, recebem atenção neste documento os seguintes itens: temas dos textos; percursos relatados nos trabalhos; conceitos, ideias, modelos que serviram de orientação ou base para os estudos, isto é, como aporte teórico, e suas fontes; insumos, noções, critérios, parâmetros que nortearam, fundamentaram ou alimentaram aspectos executivos das vias descritas nos textos, ou seja, que funcionaram como referencial metodológico, e seus trabalhos de origem.

\section{Descrição do Corpus}

O Akademikku Japanîzu Jânaru tem periodicidade anual e teve seu primeiro número publicado em junho de 2009. No site do Akademikku Japanîzu Gurûpu (2014a), encontram-se disponibilizados integralmente cinco volumes da revista. Neles, os seguintes tipos de texto são identificados: artigos de pesquisa (kenkyû ronbun), relatos de experiência (jissen hôkoku), relatos de investigação (chôsa hôkoku), notas de pesquisa (kenkyû nôto) e notas breves (tanshin).

Os requisitos de cada uma dessas categorias de texto estão expressos nas normas de submissão do periódico e são apresentados a seguir:

Artigo de Pesquisa: A partir de uma compreensão satisfatória de pesquisas passadas, estabelece um problema de pesquisa claro e, com base em dados concretos, conduz de forma lógica e com evidências a resultados originais de pesquisa

\section{$[\ldots]$}

Relato de Experiência: Expressa de maneira concreta e de fácil entendimento o propósito e o conteúdo de experiências de domínios pertinentes em um formato que possibilita o compartilhamento entre profissionais da área

Relato de Investigação: Entre outros tipos de estudo de domínios pertinentes, análise da situação corrente ou pesquisa de opinião; apresenta de forma inteligível, a partir da realização de uma análise adequada, resultados de investigação feita com base em objetivos e métodos claros

Nota de Pesquisa: Incluindo pesquisas incipientes, contém elementos que servirão de base para pesquisas futuras ou elementos que serão desenvolvidos em artigos de pesquisa de excelência 
Nota Breve: Relato que diz respeito a informações valiosas para a pesquisa e o ensino de domínios pertinentes (planos de aula, invenções etc.) (AKADEMIKKU JAPANÎZU GURÛPU, 2014b, p. 1, tradução do autor deste trabalho).

Nas cinco edições do Akademikku Japanîzu Jânaru, foram publicados 46 textos com a seguinte disposição: 10 artigos de pesquisa (21,7\% do total), 17 relatos de experiência (37\%), 6 relatos de investigação (13\%), 11 notas de pesquisa $(23,9 \%)$ e 2 notas breves $(4,3 \%)$. Foram considerados na análise desenvolvida os 10 artigos de pesquisa, os 6 relatos de investigação, 10 notas de pesquisa e as 2 notas breves -28 textos no total. Uma nota de pesquisa foi excluída porque, embora tenha sido publicada sob a categoria kenkyû nôto, se encontra sob uma subcategoria denominada relatório de atividades (katsudô hôkoku), apresentando conteúdo bastante diverso daquilo que se espera para uma nota. ${ }^{5}$ Os relatos de experiência não foram incluídos no corpus em decorrência de seu teor eminentemente prático, que destoa do interesse primário deste trabalho, que reside na pesquisa de língua japonesa acadêmica enquanto arena de constituição de saberes.

\section{Procedimentos de Pesquisa}

Serviram de insumos para este trabalho estudos que retratam a produção acadêmica de domínios ligados à administração: o exame sobre análise organizacional de Bertero e Keinert (1994), as análises de marketing de Vieira (2003), a pesquisa de empreendedorismo de Borba, Hoeltgebaum e Silveira (2011) e a investigação referente a estudos críticos em administração de Davel e Alcadipani (2003). Bertero e Keinert (1994), mediante análise de conteúdo, examinaram três itens de 184 artigos de análise organizacional: escola ou perspectiva teórica, variáveis organizacionais estudadas (assuntos, base empírica, tipos de variáveis etc.) e autores mais citados. Vieira (2003) analisou, fundamentalmente, o tema, o número de autores, a filiação acadêmica dos autores e os trabalhos citados de 272 artigos de marketing. Borba, Hoeltgebaum e Silveira (2011), por sua vez, classificaram 91 artigos de empreendedorismo quanto a seu campo de estudos e descreveram aspectos quantitativos relacionados às referências bibliográficas dos textos. Por último, Davel e Alcadipani (2003) investigaram a temática, influências teóricas, métodos e instituição de origem do primeiro autor de 80 artigos interpretados como críticos.

Esta pesquisa focalizou tema, percursos investigativos, aportes teóricos, referenciais metodológicos e fontes de 28 textos de língua japonesa acadêmica.Apresenta, pois, escopo próximo ao dos estudos citados, ainda que não tenha contiguidade temática. Características divergentes do corpus e diferenças quanto a interesses de pesquisa,

5. O texto de Horii (2009), já citado na introdução deste trabalho. 
entretanto, motivaram e exigiram uma abordagem analítica particular, de modo que as vias percorridas têm alguma semelhança com aquelas encontradas nos insumos indicados, devido à afinidade do escopo, mas são originais.

Os textos foram analisados mormente de maneira vertical. Primeiro, procedeuse ao exame dos documentos com o registro em língua portuguesa de itens relevantes (fichamento). Nesse registro, incluíram-se traduções brutas do título, resumo, palavraschave e passagens do corpo dos textos. Em seguida, mediante a consulta aos registros feitos e aos documentos originais, elaboraram-se descrições breves de cada um dos textos, contendo tema, vias, aporte teórico e referencial metodológico. A partir dessas descrições, agruparam-se os trabalhos em torno de eixos temáticos. Depois, realizou-se o registro final do tema, dos percursos investigativos, do aporte teórico e do referencial metodológico de cada um dos textos, o que envolveu a consulta às descrições breves, aos fichamentos e aos originais em língua japonesa. Ademais, concomitantemente a isso, procedeu-se à identificação, nos originais, das fontes a que se relacionam os aportes teóricos e os referenciais metodológicos registrados, assim como a sua transcrição.

Destaca-se que a localização de aporte teórico, ou seja, de conceitos, esquemas, ideias que, de um modo ou de outro, serviram como base ou orientação para os trabalhos publicados, e de referencial metodológico, isto é, de noções, insumos, critérios, parâmetros usados na parte executiva dos estudos relatados, exigiu um exame detido de citações presentes em partes variadas dos documentos japoneses - demandou avaliar o papel das citações, e não apenas encontrá-las.

\section{Resultados}

Os trabalhos foram reunidos em cinco grupos conforme seu tema: redação em língua japonesa, ensino-aprendizagem de língua japonesa, compreensão e expressão oral em japonês, citações e outros aspectos do texto japonês, outros temas. Dos 28 textos examinados, $11(39,3 \%)$ foram relacionados ao primeiro grupo, 5 (17,9\%), ao segundo e 4 trabalhos $(14,3 \%)$ puderam ser relacionados a cada um dos três grupos restantes. Nas subseções a seguir, apresentam-se os resultados obtidos a partir do agrupamento feito. ${ }^{6},{ }^{7}$

6. Neste trabalho, faz-se distinção entre as citações de caráter geral e aquelas referentes a componentes do corpus com o uso de colchetes para as últimas. Ainda, as referências dos textos japoneses examinados encontram-se em lista que precede a que contém as referências das fontes das citações de caráter geral.

7. Referências identificadas nos textos japoneses são parte dos resultados deste trabalho. Sua apresentação é feita com duas alterações principais em relação aos textos originais: hiragana, katakana e kanji foram convertidos em caracteres romanos segundo o sistema Hepburn; sinais de pontuação japoneses foram substituídos por sinais ocidentais ou espaços. Essa substituição envolveu o uso de aspas simples no lugar de “「」” e “ \lceil\rangle ”, o emprego de aspas duplas no lugar de “『』” e a utilização, conforme o caso, de barras ou espaços para a representação do ponto na altura intermediária da linha,

“.”. Esclarece-se que certa inconsistência na formatação e nos sinais de pontuação das fontes transcritas decorre da fidelidade aos textos originais examinados. 


\subsection{Redação em Língua Japonesa}

Os trabalhos reunidos neste grupo tratam, especificamente, dos seguintes temas: consciência de aprendizes quanto à redação em segunda língua [ISHIGE, 2009], formação de escritores autônomos com a técnica denominada peer response [TANAKA, 2009], processo de escrita de aprendizes de japonês que têm o inglês ou o coreano como língua materna [ISHIGE, 2011], influência do peer response em redações [TANAKA, 2011], processo de escrita de aprendizes estrangeiros de japonês [YOSHIDA, 2011], modelo do processo de escrita em segunda língua [ISHIGE, 2010], uso de língua materna no processo de escrita em língua japonesa como segunda língua [ISHIGE, 2013], significado atribuído à escrita acadêmica por aprendizes de japonês [YÔ, 2013], workshops de redação [KAGEYAMA, 2011], orientação quanto à proposição de problemas em textos de opinião [KOYAMA, 2013] e ensino de redação [TAKAHASHI, 2011].

Os percursos investigativos encontrados nos textos estão reunidos no quadro a seguir.

Quadro 1 - Percursos investigativos observados nos textos relacionados à redação em língua japonesa.

\begin{tabular}{|c|c|}
\hline Texto & Percursos Investigativos \\
\hline Ishige [2009] & $\begin{array}{l}\text { Aplicação de questionários com perguntas abertas junto a aprendizes de japonês como segunda } \\
\text { língua de níveis variados que tinham o coreano como língua materna; classificação e análise das } \\
\text { respostas }\end{array}$ \\
\hline Tanaka [2009] & $\begin{array}{l}\text { Análise de textos produzidos por aprendizes estrangeiros após atividades de peer response com um } \\
\text { software especializado de text mining (mineração de texto); estudo de entrevistas e diálogos com os } \\
\text { aprendizes e exame de protocolos de redação }\end{array}$ \\
\hline Ishige [2011] & $\begin{array}{l}\text { Experimento registrado em áudio e vídeo em que aprendizes de japonês relataram o que pensavam } \\
\text { enquanto escreviam textos; tratamento estatístico dos dados e agrupamento dos resultados em } \\
\text { categorias }\end{array}$ \\
\hline Tanaka [2011] & $\begin{array}{l}\text { Análise comparativa entre textos feitos por aprendizes de japonês com a aplicação de atividades de } \\
\text { peer response; tratamento estatístico dos dados }\end{array}$ \\
\hline Yoshida [2011] & $\begin{array}{l}\text { Experimento em que aprendizes de japonês escreveram textos e relataram seus pensamentos; } \\
\text { entrevistas com os participantes do experimento; comparação entre os processos de escrita de } \\
\text { aprendizes com textos bem e mal avaliados }\end{array}$ \\
\hline Ishige [2010] & $\begin{array}{l}\text { Experimento em que aprendizes de japonês que tinham o inglês ou o chinês como língua materna } \\
\text { relataram o que pensavam enquanto escreviam textos em japonês }\end{array}$ \\
\hline Ishige [2013] & $\begin{array}{l}\text { Experimento em que aprendizes de japonês que tinham o chinês como língua materna relataram o } \\
\text { que pensavam enquanto escreviam textos em japonês; análise de dados a partir de categorias } \\
\text { anteriores com tratamento estatístico }\end{array}$ \\
\hline Yô [2013] & $\begin{array}{l}\text { Aplicação de questionários por meio eletrônico e análise dos dados obtidos com software } \\
\text { especializado }\end{array}$ \\
\hline Kageyama [2011] & Análise da proposta de trabalho dos workshops de redação mediante uma teoria de psicologia \\
\hline Koyama [2013] & $\begin{array}{l}\text { Apresentação de um problema, revisão acerca do assunto tratado e reunião e discussão de exemplos } \\
\text { com proposições para o ensino }\end{array}$ \\
\hline Takahashi [2011] & $\begin{array}{l}\text { Experimento em sala de aula com exercícios de redação e aplicação de questionários para a } \\
\text { avaliação dos resultados }\end{array}$ \\
\hline
\end{tabular}




\section{Os aportes teóricos identificados nos trabalhos relacionados à redação em língua}

japonesa, assim como suas fontes, estão registrados no Quadro 2.

Quadro 2 - Aportes teóricos observados nos textos relacionados à redação em língua japonesa e suas fontes.

\begin{tabular}{|c|c|c|}
\hline Texto & Aporte Teórico & Fonte(s) \\
\hline \multirow{3}{*}{ Ishige [2009] } & \multirow{3}{*}{$\begin{array}{l}\text { Conceito de sentimento de } \\
\text { capacidade (yûnôkan) }\end{array}$} & $\begin{array}{l}\text { Deci, E. L., \& Ryan, R. M. (Eds.), (2002) Handbook of self-determination } \\
\text { research. Rochester, NY: University of Rochester Press. }\end{array}$ \\
\hline & & $\begin{array}{l}\text { White, R. (1959) Motivation Reconsidered: the Concept of Competence. } \\
\text { Psychological Review, 66, 297-333. }\end{array}$ \\
\hline & & $\begin{array}{l}\text { Kage Masaharu (2004) 'Dôkizuke kenkyû e no izanai' Uebuchi Hisashi (Hen) } \\
\text { "Dôkizuke kenkyû no saizensen” Dai } 1 \text { Shô Kitaôji Shobô, 1-28. }\end{array}$ \\
\hline \multirow{3}{*}{$\begin{array}{l}\text { Tanaka } \\
\text { [2009] }\end{array}$} & \multirow{3}{*}{$\begin{array}{l}\text { Fundamentos de peer } \\
\text { response }\end{array}$} & $\begin{array}{l}\text { Ikeda Reiko (2004) 'Nihongo gakushû ni okeru gakushûsha dôshi no sôgo } \\
\text { jogen (pia resuponsu)' "Nihongogaku" } 23(1), 36-50 \text { Meiji Shoin }\end{array}$ \\
\hline & & $\begin{array}{l}\text { Ikeda Reiko (2007a) 'Pia responsu' Ikeda Reiko / Tateoka Yôko "Pia Râningu } \\
\text { Nyûmon" Hitsuji Shobô }\end{array}$ \\
\hline & & $\begin{array}{l}\text { Ikeda Reiko (2007b) 'Hihanteki ronriteki shikôryoku to komyunikêshonryoku } \\
\text { ikusei no tame no nihongo hyôgenhô - Nihongo sakubun pia resuponsu } \\
\text { no ôyô - Dokuritsu Gyôsei Hôjin Kokuritsu Kokugo Kenkyûjo Hen } \\
\text { "Nihongo Kyôiku Nenkan } 2007 \text { Nendo Ban" 32-47 Kuroshio Shuppan }\end{array}$ \\
\hline \multirow[t]{2}{*}{ Ishige [2011] } & \multirow[t]{2}{*}{$\begin{array}{l}\text { Noções sobre o processo } \\
\text { de escrita }\end{array}$} & $\begin{array}{l}\text { Hayes, J. \& Flower, L. (1980) Identifying the organization of writing processes. } \\
\text { In Gregg, L. \& Steinberg, E. (Eds.), Cognitive processes in writing. } \\
\text { Hillsdale, N.J.: Lawrence Erlbaum Associates. }\end{array}$ \\
\hline & & Uchida Nobuko (1999) "Hattatsu Shinrigaku" Iwanami Shoten \\
\hline \multirow{2}{*}{$\begin{array}{l}\text { Tanaka } \\
\text { [2011] }\end{array}$} & Conceito de peer response & $\begin{array}{l}\text { Ikeda Reiko (2007) 'Dai } 4 \text { shô pia resuponsu', Ikeda Reiko / Tateoka Yôko } \\
\text { "Pia râningu nyûmon" Hitsuji Shobô }\end{array}$ \\
\hline & $\begin{array}{l}\text { Critério para verificar } \\
\text { mudanças nas redações } \\
\text { revisadas }\end{array}$ & $\begin{array}{l}\text { FAIGLEY, L. \& WITTE, S.P. (1981) Analyzing revision. College Composition } \\
\text { and Communication, 32, 400-414 }\end{array}$ \\
\hline $\begin{array}{c}\text { Yoshida } \\
\text { [2011] }\end{array}$ & Não localizado & - \\
\hline Ishige [2010] & Não localizado & - \\
\hline Ishige [2013] & $\begin{array}{l}\text { Categorias de } \\
\text { comportamento quanto ao } \\
\text { uso de língua materna na } \\
\text { redação em japonês }\end{array}$ & $\begin{array}{l}\text { Ishige Junko (2010) 'Bogo shiyô no kanten kara mita eigo bogo washa no } \\
\text { nihongo sakubun katei' "Nihon Kyôiku Shinri Gakkai Dai } 52 \text { Kai Sôkai } \\
\text { Ronbunshû" } 506 \text {. }\end{array}$ \\
\hline
\end{tabular}

Kadokura Masami (2006) "Manabi to komyunikêshon" no nihongoryoku: Akademikku Japanîzu kara no hasshin' Kadokura Masami / Tsutsui Yôich / Miyake Kazuko "Akademikku Japanîzu no chôsen" Hitsuji Shobô, 3-20.

Chinami Kyôko / Chen Junsen / Lee Kil-Young / Marîna Karyujinowa / Satô Sekiko (2012) 'Akademikku japanîzu kyôiku no igi - Nihongo ni yoru kenkyû no jushin hasshin o tsûjite mi ni tsuku chikara wa nani ka -' "Nihongo kyôiku kokusai kenkyû taikai Nagoya 2012 yokôshû dai 2 bun satsu", 34-35

Nitsû Nobuko / Ôshima Yayoi / Yamamoto Fumiko / Satô Sekiko / Chinami Kyôko (2004) 'Akademikku raitingu kyôiku no kadai' "Nihongo Kyôiku Gakkai 2004 nen shunki taikai yokôshû", 285-296.

Hosokawa Hideo (2008) "Ronbun sakusei no dezain: Têma no hakken kara kenkyû no kôchiku e" Tôkyô Tosho.

\begin{tabular}{|c|c|c|}
\hline $\begin{array}{l}\text { Kageyama } \\
\text { [2011] }\end{array}$ & Teoria da escolha & $\begin{array}{l}\text { Wiriamu Gurassâ (2000) / Kakitani Masaki Yaku "Gurassâ Hakushi no } \\
\text { sentakuriron shiawase na ningen kankei o kizuku tame ni" Achîbumento } \\
\text { Shuppan }\end{array}$ \\
\hline \multirow{4}{*}{$\begin{array}{l}\text { Koyama } \\
\text { [2013] }\end{array}$} & \multirow{4}{*}{$\begin{array}{l}\text { Definições e características } \\
\text { da proposição de problemas } \\
\text { (mondai teiki) }\end{array}$} & $\begin{array}{l}\text { Ishiguro Kei (2008) "Nihongo no bunshô rikai katei ni okeru yosoku no kata to } \\
\text { kinô" Hitsuji Shobô }\end{array}$ \\
\hline & & $\begin{array}{l}\text { Ishiguro Kei (2009) "Yoku wakaru bunshô hyôgen no gijutsu II - Bunshô kôsei } \\
\text { hen - 'Shinpan'" Meiji Shoin }\end{array}$ \\
\hline & & $\begin{array}{l}\text { Sakai Satoki (2009) "Kore kara repôto/sotsuron o kaku wakamono no tame ni" } \\
\text { Kyôritsu Shuppan }\end{array}$ \\
\hline & & $\begin{array}{l}\text { Hamada Mari / Hirao Tokuko / Yui Kikuko (2009) "Daigakusei to ryûgakusei } \\
\text { no tame no ronbun wâkubukku" (Kaiteiban) 26-28, 64-68 }\end{array}$ \\
\hline \multirow{3}{*}{$\begin{array}{l}\text { Takahashi } \\
\text { [2011] }\end{array}$} & $\begin{array}{l}\text { Orientações para o ensino } \\
\text { de redação }\end{array}$ & $\begin{array}{l}\text { Cohen, M., \& Riel, M. (1989). The Effect of Distant Audiences on Students' } \\
\text { Writing. American Educational Research Journal, 26, 143-159. }\end{array}$ \\
\hline & $\begin{array}{l}\text { Noções de educação } \\
\text { empreendedora }\end{array}$ & $\begin{array}{l}\text { Takahashi Kaoru / Muramatsu Hiroyuki / Tsubakimoto Mio / Kon Takako / Kon } \\
\text { Toshitsugu / Muraoka Akira / Horita Tatsuya (2009) Gengoryoku ikusei } \\
\text { kara miru chûgakkô antorepurenâ kyôiku jissen no hyôka Nihon Kyôiku } \\
\text { Kôgakkai Ronbunshi } 33 \text { (Suppl.), } 97-100\end{array}$ \\
\hline & $\begin{array}{l}\text { A ideia de reflexão presente } \\
\text { no processo de escrita }\end{array}$ & $\begin{array}{l}\text { Bereiter, C., \& Scardamalia, M. (1987). The psychology of written } \\
\text { composition, New Jersey: Lawrence Erlbaum Associates. }\end{array}$ \\
\hline
\end{tabular}

110 ARAGÃO, Rodrigo Moura Lima de. Estudos de Língua Japonesa Acadêmica: Retratos... 
Por último, os referenciais metodológicos observados nos textos deste primeiro grupo encontram-se reunidos no Quadro 3, também acompanhados de suas fontes.

Quadro 3 - Referenciais metodológicos localizados nos textos relacionados à redação em língua japonesa e suas fontes.

\begin{tabular}{|c|c|c|}
\hline Texto & Referencial Metodológico & Fonte(s) \\
\hline Ishige [2009] & Não localizado & - \\
\hline Tanaka [2009] & Fundamentos de peer response & $\begin{array}{l}\text { Ikeda Reiko (2007a) 'Pia resuponsu' lkeda Reiko / Tateoka Yôko } \\
\text { "Pia râningu nyûmon" Hitsuji Shobô }\end{array}$ \\
\hline \multirow{3}{*}{ Ishige [2011] } & $\begin{array}{l}\text { Insumos quanto aos temas } \\
\text { usados nas atividades }\end{array}$ & $\begin{array}{l}\text { Ishibashi Reiko (2002) "Dai } 2 \text { gengo shûtoku ni okeru dai } 1 \text { gengo } \\
\text { no kan'yo" Kazama Shobô } \\
\text { KOBAYASHI, H. \& RINNERT, C. (1992) Effects of first Language } \\
\text { on second language writing: Translation versus Direct } \\
\text { Composition. Language Learning 42, pp.183-215. }\end{array}$ \\
\hline & Categorias de análise & $\begin{array}{l}\text { Ishige Junko (2010b) 'Bogo shiyô no kanten kara mita eigo bogo } \\
\text { washa no nihongo sakubun katei' Nihon Kyôiku Shinri Gakkai } \\
\text { Dai } 52 \text { Kai Sôkai Ronbunshû p506 }\end{array}$ \\
\hline & $\begin{array}{l}\text { Citação de Vygotsky sobre o } \\
\text { método empregado }\end{array}$ & Não localizada na lista de referências bibliográficas \\
\hline \multirow{3}{*}{ Tanaka [2011] } & $\begin{array}{l}\text { Modo de introduzir o peer } \\
\text { response em sala de aula }\end{array}$ & $\begin{array}{l}\text { Ikeda Reiko (2007) 'Dai } 4 \text { shô pia resuponsu', Ikeda Reiko / } \\
\text { Tateoka Yôko "Pia râningu nyûmon" Hitsuji Shobô }\end{array}$ \\
\hline & $\begin{array}{l}\text { Desenho experimental de } \\
\text { pesquisa passada }\end{array}$ & $\begin{array}{l}\text { Tanaka Nobuyuki (2010) 'Gakushûsha sakubun ni taisuru pia } \\
\text { fîdobakku no bunseki - Fîdobakku no kyôji to suikô no futatsu } \\
\text { no kanten kara -' "Koide Kinen Nihongo Kyôiku Kenkyûkai } \\
\text { Ronbunshû" } 18,81-94\end{array}$ \\
\hline & $\begin{array}{l}\text { Critério para verificar mudanças } \\
\text { nos textos revisados }\end{array}$ & $\begin{array}{l}\text { FAIGLEY, L. \& WITTE, S.P. (1981) Analyzing revision. College } \\
\text { Composition and Communication, 32, 400-414 }\end{array}$ \\
\hline \multirow{2}{*}{ Yoshida [2011] } & $\begin{array}{l}\text { Noção sobre o método de } \\
\text { registro do pensamento via fala }\end{array}$ & $\begin{array}{l}\text { Nakajima Yoshiaki / Andô Kiyoshi / Koyasu Masuo / Sakano Yûji / } \\
\text { Shigemasu Kazuo / Tachibana Masao / Hakoda Yûji (1999) } \\
\text { "Shinrigaku jiten" Yûhikaku }\end{array}$ \\
\hline & $\begin{array}{l}\text { Critérios para a avaliação de } \\
\text { textos }\end{array}$ & $\begin{array}{l}\text { Ishibashi Reiko (2002) "Dai } 2 \text { gengo shûtoku ni okeru dai } 1 \text { gengo } \\
\text { no kan'yo - Nihongo gakushûsha no sakubun sanshutsu kara } \\
\text {-" Kazama Shobô }\end{array}$ \\
\hline Ishige [2010] & $\begin{array}{l}\text { Referencial para a escolha dos } \\
\text { temas das redações }\end{array}$ & $\begin{array}{l}\text { Ishibashi Reiko (2002) "Dai } 2 \text { gengo shûtoku ni okeru dai } 1 \text { gengo } \\
\text { no kan'yo" Kazama Shobô } \\
\text { KOBAYASHI, H. \& RINNERT, C. (1992) Effects of first Language } \\
\text { on second language writing: Translation versus Direct } \\
\text { Composition. Language Learning 42, pp.183-215. }\end{array}$ \\
\hline \multirow{3}{*}{ Ishige [2013] } & $\begin{array}{l}\text { Noção sobre o método de } \\
\text { registro do pensamento via fala }\end{array}$ & $\begin{array}{l}\text { Vygotsky L. (Shibata Yoshimatsu Yaku) (2001) "Shikô to gengo" } \\
\text { Shindokushosha }\end{array}$ \\
\hline & \multirow{2}{*}{$\begin{array}{l}\text { Referencial para a escolha dos } \\
\text { temas das redações }\end{array}$} & $\begin{array}{l}\text { Ishibashi Reiko (2002) "Dai } 2 \text { gengo shûtoku ni okeru dai } 1 \text { gengo } \\
\text { no kan'yo" Kazama Shobô }\end{array}$ \\
\hline & & $\begin{array}{l}\text { KOBAYASHI, H. \& RINNERT, C. (1992) Effects of first Language } \\
\text { on second language writing: Translation versus Direct } \\
\text { Composition. Language Learning 42, 183-215. }\end{array}$ \\
\hline Yô [2013] & $\begin{array}{l}\text { Referencial para a análise de } \\
\text { dados }\end{array}$ & $\begin{array}{l}\text { Satô Ikuya (2008) “Jissenshitsuteki dêta bunseki nyûmon-QDA } \\
\text { sofuto o katsuyô suru” Shin'yôsha. }\end{array}$ \\
\hline Kageyama [2011] & Não localizado & - \\
\hline Koyama [2013] & Não localizado & - \\
\hline \multirow{3}{*}{ Takahashi [2011] } & \multirow{3}{*}{$\begin{array}{l}\text { Insumos para a elaboração dos } \\
\text { exercícios aplicados em sala }\end{array}$} & $\begin{array}{l}\text { Araki Shôko / Tsutsui Yôichi / Kôgo Chiharu (2000) "Jiko hyôgen } \\
\text { ryoku no kyôshitsu” Jôhô Sentâ Shuppankyoku }\end{array}$ \\
\hline & & $\begin{array}{l}\text { Ôshima Yayoi / Ikeda Reiko / Ôba Rieko / Kanô Naomi / Takahashi } \\
\text { Yoshio / Iwata Natsuho (2005) "Pia de manabu daigakusei no } \\
\text { nihongo hyôgen" Hitsuji Shobô }\end{array}$ \\
\hline & & Outras fontes \\
\hline
\end{tabular}




\subsection{Ensino-Aprendizagem de Língua Japonesa}

Os trabalhos incluídos neste grupo abordam, em termos específicos, os seguintes temas: aprendizagem colaborativa no ensino de japonês de especialidade (técnico) na pós-graduação [KAMIMURA, 2012]; aprendizado de língua japonesa na vida de estudantes estrangeiros [NAKAYAMA, 2011]; japonês acadêmico em instituições de ensino superior estrangeiras e aprendizado de língua japonesa por universitários estrangeiros [SEOMA, 2013]; coordenação entre o aprendizado de língua japonesa e o aprendizado acadêmico, com ênfase em estudantes de ensino médio com histórico de vivência e estudo no exterior [TAKAHASHI; IGUSA, 2010]; influência de estratégias de aprendizado na aquisição de regras aplicadas de designação (shijiyôhô) [SON, 2010].

Os percursos identificados nos trabalhos deste grupo foram: atividades variadas aplicadas em sala, como avaliações diagnósticas, exercícios individuais e em dupla, enquetes e entrevistas [KAMIMURA, 2012]; entrevistas individuais com um aprendiz de japonês e composição de sua história de vida [NAKAYAMA, 2011]; entrevistas semiestruturadas com universitários taiwaneses mais o agrupamento e a análise do conteúdo das entrevistas transcrito [SEOMA, 2013]; exame de dados e informações e apresentação de uma solução para uso no ensino [TAKAHASHI; IGUSA, 2010]; aplicação de questionários junto a aprendizes de japonês como segunda língua e como língua estrangeira e análise estatística dos dados obtidos [SON, 2010].

No Quadro 4, encontram-se reunidos os elementos que parecem desempenhar o papel de aporte teórico nos trabalhos deste grupo, juntamente com suas fontes.

No Quadro 5, por sua vez, estão expressos os referenciais metodológicos observados nos trabalhos, acompanhados de suas respectivas fontes. 
Quadro 5 - Referenciais metodológicos identificados nos textos relacionados ao ensinoaprendizagem de língua japonesa e suas fontes.

\begin{tabular}{|c|c|c|}
\hline Texto & Referencial Metodológico & Fonte(s) \\
\hline $\begin{array}{c}\text { Kamimura } \\
{[2012]}\end{array}$ & Não identificado & - \\
\hline \multirow{2}{*}{$\begin{array}{l}\text { Nakayama } \\
{[2011]}\end{array}$} & \multirow{2}{*}{$\begin{array}{l}\text { Concepção de história de vida } \\
\text { como uma estória ou narrativa } \\
\text { (monogatari) }\end{array}$} & $\begin{array}{l}\text { Burûnâ, Jerômu (1998) "Kanô sekai no shinri" Tanaka Ichirô Yaku } \\
\text { Misuzu Shobô" }\end{array}$ \\
\hline & & $\begin{array}{l}\text { Rikûru, Pôru (1987) “Jikan to monogatari I - Monogatari to jikansei no } \\
\text { junkan / rekishi to monogatari” Kume Hiroshi Yaku Shin'yôsha }\end{array}$ \\
\hline Seoma [2013] & Não identificado & - \\
\hline $\begin{array}{l}\text { Takahashi e } \\
\text { Igusa [2010] }\end{array}$ & Não identificado & - \\
\hline \multirow{7}{*}{ Son [2010] } & \multirow{2}{*}{$\begin{array}{l}\text { Noções sobre falantes de } \\
\text { segunda língua e de língua } \\
\text { estrangeira e sobre o } \\
\text { aprendizado de segunda língua }\end{array}$} & $\begin{array}{l}\text { Collentine, J. (2004) The effects of learning contexts on } \\
\text { morphosyntactic and lexical development. Studies in Second } \\
\text { Language Acquisition, 26-2, 227-248 }\end{array}$ \\
\hline & & $\begin{array}{l}\text { Wilkinson, S. (1998) Study abroad from the participants' perspective: A } \\
\text { challenge to common beliefs, Foreign Language Annals, 31-1, 23- } \\
39\end{array}$ \\
\hline & \multirow{3}{*}{$\begin{array}{l}\text { Insumos para a elaboração de } \\
\text { perguntas sobre estratégias de } \\
\text { aprendizado }\end{array}$} & $\begin{array}{l}\text { An Yongsu (2001) 'Nihongo gakushûsha no shijishi no shiyô ishiki ni } \\
\text { mirareru tokuchô - Kankokujin gakushûsha to chûgokujin } \\
\text { gakushûsha o hikakushite' "Dai } 2 \text { Gengo toshite no Nihongo no } \\
\text { Shûtoku Kenkyû" } 4,5-22\end{array}$ \\
\hline & & $\begin{array}{l}\text { An Yongsu (2008) 'Kankokujin gakushûsha no shijishi no shiyô ishiki ni } \\
\text { kansuru ichikôsatsu - Shijishi no tesuto no ato ni jisshishita jiyû } \\
\text { kijutsu no bunseki kara -' "Ibaraki Daigaku Ryûgakusei Sentâ Kiyô" } \\
\text { 6, } 61-76\end{array}$ \\
\hline & & $\begin{array}{l}\text { Mukôyama Yôko (2007) 'Bunpô gakushû ni kansuru shin'nen taido, } \\
\text { gakushû sutoratejî, gakushû seika no kanren - Anjiteki kinôteki } \\
\text { shidô no kontekusuto no naka de' "Nihongo Kyôiku Ronshû" 23, 17- } \\
32\end{array}$ \\
\hline & \multirow{2}{*}{$\begin{array}{l}\text { Modelo sobre regras aplicadas } \\
\text { de designação (shijiyôhô) e } \\
\text { perguntas baseadas nesse } \\
\text { modelo }\end{array}$} & $\begin{array}{l}\text { Son Maniku (1991) 'Nihongo kyôiku no tame no nikkan shijishi no taishô } \\
\text { kenkyû - 'Ko so a' to 'i geu jeo' to no yôhô ni tsuite' "Nihongo } \\
\text { Kyôiku" } 75,136-152\end{array}$ \\
\hline & & $\begin{array}{l}\text { Son Aii (2008) 'Dai ni gengo oyobi gaikokugo toshite no nihongo } \\
\text { gakushûsha ni okeru higenba shiji no shûtoku - Taiwanjin nihongo } \\
\text { gakushûsha o taishô ni' "Sekai no Nihongo Kyôiku" } 18,163-183\end{array}$ \\
\hline
\end{tabular}

*O nome correto do tradutor parece ser Tanaka Kazuhiko.

\subsection{Compreensão e Expressão Oral em Japonês}

Os trabalhos relacionados à compreensão e expressão oral em japonês tratam, especificamente, dos seguintes assuntos: percepção de estudantes de doutorado japoneses e estrangeiros quanto a apresentações orais [NISHINA, 2013], operações de abstração e concretização que acompanham atividades complexas de uso oral da língua [YAMAMOTO, 2011], compreensão de palestras acadêmicas em língua japonesa por estudantes estrangeiros [OGAWA, 2011] e relação entre atividades de autoavaliação e o desempenho de alunos em aulas de conversação em japonês [SAIKI; NAKAMURA; OGASA, 2012].

No que se refere às vias relatadas nos trabalhos, os seguintes cursos foram identificados: entrevistas semiestruturadas em grupo com pós-graduandos japoneses e estrangeiros [NISHINA, 2013], revisão e discussão teóricas acompanhadas da análise de um caso real [YAMAMOTO, 2011], aplicação de questionários mais análise 
estatística dos dados obtidos [OGAWA, 2011], exame comparativo entre o conteúdo de formulários de autoavaliação preenchidos por estudantes e gravações de exercícios orais [SAIKI; NAKAMURA; OGASA, 2012].

No estudo acerca da percepção de pós-graduandos quanto a apresentações orais [NISHINA, 2013] e no texto a respeito de operações de abstração e concretização pertinentes a atividades complexas de uso oral da língua [YAMAMOTO, 2011], não foi identificado aporte teórico, tampouco referencial metodológico. No último, uma teoria designada como "pirâmide da experiência" (keiken ensui), é revisada e discutida. Isso, contudo, não parece fazer dessa teoria seu aporte teórico ou referencial metodológico; trata-se tão somente da matéria de seu exame. ${ }^{8}$

No trabalho sobre a compreensão de estudantes estrangeiros de palestras acadêmicas em japonês [OGAWA, 2011], também não foram identificados elementos que sirvam de base ou orientação para o trabalho (aporte teórico). Identificou-se, todavia, referencial metodológico quanto ao conteúdo dos questionários usados na pesquisa, que foi definido a partir de estudos passados. As fontes desse referencial são estas:

Hirao Tokuko (1999) 'Kôgi chôkai nôryoku ni kansuru ichikôsatsu - Kôgi chôkai no tokuchô to nihongo gakushûsha ga kakaeru mondaiten -' "Nihongo Nihonbunka" 25, $1-21$

$[\ldots]$

Ogawa Miyako (2011) 'Daigaku gakubu ni okeru ryûgakusei no nihongo komyunikêshon nôryoku oyobi gakushû sukiru no jittai ni kansuru kenkyû - Kyôbunsan kôzô bunseki o tôshite -' "Senshû Daigaku Gaikokugo Kyôiku Ronshû" Dai 39 Gô, 77-92 [OGAWA, 2011, p. 96-97].

Por último, no trabalho que lida com a relação entre atividades de autoavaliação e desempenho de aprendizes na conversação [SAIKI; NAKAMURA; OGASA, 2012], não foi verificado aporte teórico. Na seção do texto acerca de pesquisas passadas, há muitos estudos recuperados, mas a substância de nenhum deles parece desempenhar o papel de norte ou base. Em uma nota pós-texto, no entanto, localizam-se insumos para as atividades relatadas no estudo, que podem ser interpretados como referencial metodológico no tipo de trabalho em questão:

- $\quad$ Boikuman Fusako / Miyatani Atsumi / Komuro Rî Ikuko (2006) "Nihongo nama chûkei shochûkyû hen" Kuroshio Shuppan

• Oyanagi Noboru (2002) “Nyû apurôchi chûkyû nihongo ‘kisohen’ kaiteiban” Nihongo Kenkyû Sha

8. A fonte dessa teoria, no molde da Associação Brasileira de Normas Técnicas, é esta: DALE, Edgar. Audio-visual methods in teaching. $3^{\text {rd }}$ ed. [S.1.]: Dryden Press, Holt, Rinehart and Winston, Inc., 1969 [1946]. 
- Oyanagi Noboru / Iwai Noriko (2002) "Nyû apurôchi chûkyû nihongo 'kanseihen"” Nihongo Kenkyû Sha [SAIKI; NAKAMURA; OGASA, 2012, p. 57].

\subsection{Citações e outros aspectos do texto japonês}

Em termos específicos, os trabalhos reunidos neste grupo tratam dos seguintes temas: citações presentes em artigos japoneses [NITSÛ, 2009], objetivos do uso de citações com a forma -wa-teiru [SHIZUMA, 2010], estruturas argumentativas em textos de opinião [IJÛIN, 2010] e padrões de frases japonesas [EYA, 2011].

Os percursos relatados nos textos são: exame de citações de artigos de campos diversos com a observação de sua posição e tipo mais a proposição de um modelo descritivo [NITSÛ, 2009], análise e classificação de citações presentes em artigos de humanidades e verificação da incidência das categorias empregadas [SHIZUMA, 2010], estudo de textos feitos por japoneses com a expressão tashika ni e comparação com textos escritos por taiwaneses e coreanos [IJÛIN, 2010] e proposição de uma versão preliminar de um modelo para descrever padrões frasais japoneses e demonstração de sua aplicação em frases [EYA, 2011].

No que diz respeito à presença de aporte teórico e referencial metodológico nos trabalhos deste grupo, verificou-se, primeiro, que, no exame da posição e do tipo de citações [NITSÛ, 2009], apesar de haver muitos trabalhos pertinentes no corpo do estudo, não parece estar registrado um aporte teórico. Por outro lado, desempenham o papel de referencial metodológico tipos e definições de categorias de artigos pertencentes a estudo anterior da autora (com colaboradores) e critérios para equilibrar amostras das áreas do conhecimento envolvidas. As fontes desse referencial são estas:

\footnotetext{
Nitsû Nobuko / Ôshima Yayoi / Chinami Kyôko / Satô Sekiko / Yamamoto Fumiko 'Ronjiru kôi e no rikai o susumeru ronbun / repôto sakusei shien hyôgenshû no kaihatsu' "Senmon Nihongo Kyôiku” 10, 53-58

$[\ldots]$

Fujita Setsuko (2006) 'Kokunai kagaku gijutsu kei gakkaishi no tôkô kitei no bunseki: Sanshô bunken no kijutsu, chosakuken o chûshin to shite (II)' "Jôhô Kanri”" 49-11, 723-734 Fujita Setsuko (2006) 'Kokunai jinbun shakai kagaku kei gakkaishi no tôkô kitei no bunseki (II)' "Jôhô Kanri” 49-11, 622-631 [NITSÛ, 2009, p. 74].
}

Já no estudo de citações com a forma -wa-teiru [SHIZUMA, 2010], desempenham o papel de aporte teórico e o de referencial metodológico um modelo referente a citações e formulações anteriores sobre os objetivos de citações. As fontes de onde foram extraídos o aporte e o referencial são estas: 
Sadoshima Saori / Yoshino Ayako (2008) "Kore kara kenkyû o kaku hito no tame no gaidobukku" Hitsuji Shobô

Nitsû Nobuko (2009) 'Ronbun no in'yô ni kansuru kisoteki chôsa to in’yô moderu no shian' "Akademikku Japanîzu Jânaru" (I) Akademikku Japanîzu Gurûpu, 65-74 [SHIZUMA, 2010, p. 100].

No trabalho acerca de estruturas argumentativas com tashika ni [IJÛIN, 2010], por sua vez, não foram localizados aporte teórico e referencial metodológico. As citações presentes no texto têm a função, sobretudo, de evidenciar sua importância e originalidade, mas não expõem elementos teóricos norteadores ou basilares do estudo nem itens que alimentem o trabalho metodologicamente.

Por último, no estudo sobre padrões de frases japonesas [EYA, 2011], identificou-se como aporte teórico o conceito de contextualização (bunmyakuka). Esse conceito remete às fontes japonesas listadas a seguir, todas do mesmo autor:

Kawaguchi Yoshikazu (2002) “Bunmyakuka' ni yoru ôyô nihongo kenkyû - Bunpô kômoku no teishutsujun saikô -' "Waseda Nihongo Kenkyû" 11

(2004) 'Gakushûsha no tame no hyôgen bunpô - 'Bunmyakuka' ni yoru 'hatarakikakeru hyôgen' to 'kataru hyôgen no kyôiku -' "AJALT” 27 Kokusai Nihongo Fukyû Kyôkai

(2005) 'Hyôgen kyôiku e no dôtei - 'Kataru hyôgen' wa ika ni shite umareta ka -'

“Kôza Nihongo Kyôiku” Dai 41 Bunsatsu Waseda Daigaku Nihongo Kenkyû Kyôiku Sentâ (2006) 'Nihongo kyôiku ni okeru bunpô - Kôzô kara kinô e, sara ni, sono saki e' "Waseda Daigaku Nihongo Kyôiku no Rekishi to Tenbô" Aruku [EYA, 2011, p. 106-107].

No que se refere a referencial metodológico, nada que pareça desempenhar essa função foi observado no trabalho.

\subsection{Outros Temas ${ }^{9}$}

Os estudos reunidos neste grupo abordam os seguintes temas: avaliação da proficiência em língua japonesa [KADOKURA, 2009], glossário de termos acadêmicos japoneses [SUMI, 2010], formação de tutores para centros de redação [ÔTA et al., 2013] e fatores decisivos para a permanência de estudantes estrangeiros no Japão após o terremoto de março de 2011 [OGASA, 2012].

No que diz respeito às vias descritas nos trabalhos, os seguintes percursos foram identificados: análise de documento (syllabus) com diretrizes e conteúdo e de questões do

9. Nesta subseção, há excertos com menos de 3 linhas dos trabalhos examinados que têm fonte menor e recuo maior. Apesar de não ser o padrão para citações curtas, esclarece-se que tal formatação foi usada para conferir destaque também a esses dados. 
Nihon Ryûgaku Shiken acompanhada da proposição de alterações na prova [KADOKURA, 2009], construção de um glossário com termos acadêmicos básicos e relato de usos do glossário em situações variadas de ensino [SUMI, 2010], exame e agrupamento em categorias do conteúdo de folhas de trabalho (worksheets) preenchidas por tutores novatos de um centro de redação [ÔTA et al., 2013] e entrevistas semiestruturadas com o uso de uma abordagem chamada teoria fundamentada em dados [OGASA, 2012].

No trabalho acerca da avaliação de proficiência em língua japonesa [KADOKURA, 2009], não foram localizados aporte teórico e referencial metodológico. A autora desenvolve suas proposições com a ideia de "qualidade de múltiplos textos" (fukutekisutosei), que foi elaborada por ela a partir de elementos de outras fontes.

Já no documento que relata a elaboração de um glossário [SUMI, 2010], a visão do japonês acadêmico enquanto educação cultural parece servir de orientação - aporte teórico. Essa visão ancora-se na seguinte fonte japonesa:

Kadokura Masami / Tsutsui Yôichi / Miyake Kazuko (Hen) (2006) “Akademikku japanîzu no chôsen" Hitsuji Shobô [SUMI, 2010, p. 19].

Ademais, elementos de trabalhos que envolveram a elaboração de glossários aparecem no texto como referencial metodológico. Por seu teor no texto ilustrar diferentes enfoques usados na construção de glossários, as fontes japonesas a seguir são interpretadas como principais entre todas as citadas no documento:

Kokuritsu Kokugo Kenkyûjo (2000) "Nihongo kihon goi - Bunken kaidai to kenkyû" Meiji Shoin

Komiya Chizuko (2005) 'Rikôkei ryûgakusei no tame no kagaku no senmongo - Kôkô kyôkasho no sakuin chôsa ni yoru sentei' "Senmon Nihongo Kyôiku Kenkyû" Dai 7 Gô, 29-34 [SUMI, 2010, p. 19].

No trabalho a respeito da formação de tutores para centros especializados em redação [ÔTA et al., 2013], por sua vez, noções sobre tais centros e seus tutores aparentemente ocupam o lugar de aporte teórico. Entre as fontes citadas no texto, as listadas abaixo parecem as mais importantes enquanto orientação e base teórica:

Sadoshima Saori (2009) 'Jiritsu shita kakite o sodateru - Taiwa ni yoru kakinaoshi -' "Kokugoka Kyôiku” 66, pp. 11-18

$[\ldots]$

FUJIOKA, M. (2011) 'Amerika no raitingu sentâ ni okeru riron to jissen - Nihon no daigaku raitingu sentâ e no shisa -' "Kinki Daigaku Kyôyô Gaikokugo Kyôiku Sentâ Kiyô Gaikokugohen" 2 (1), pp. 205-224 


\section{$[\ldots]$}

NORTH, S. M. (1984). The idea of a writing center. College English, 46(5), 433-446. [ÔTA et al., 2013, p. 10].

Já na qualidade de referencial metodológico, identificou-se no documento uma fonte que trata de análise de conteúdo:

Arima Akie (2007) "Naiyô bunseki no hôhô" Nakanishiya Shuppan [ÔTA et al., 2013, p. 10].

Por último, no documento que trata dos fatores decisivos para a permanência de estudantes estrangeiros no Japão pós-desastre [OGASA, 2012], não foi localizado aporte teórico, apenas um referencial metodológico, que se relaciona com a aplicação da teoria fundamentada em dados. A fonte japonesa a que o referencial remete é esta:

Kinoshita Yasuhito (2003) "Guraundeddo seorî apurôchi no jissen” Kôbundô [OGASA, 2012, p. 50].

\section{Discussão}

Os resultados apresentados revelam grande variedade de temas, percursos investigativos, aportes teóricos, referenciais metodológicos e fontes no domínio dos estudos de língua japonesa acadêmica. Os retratos esboçados sugerem um campo de investigação ainda em fase de instituição, em que bases estão sendo formadas a partir de matérias-primas de origens diversas.

Os temas registrados apontam alternativas possíveis para desenvolver frentes de pesquisa sobre a língua japonesa acadêmica, inclusive no Brasil. A maior parcela dos estudos examinados trata de assuntos relacionados à redação em língua japonesa, mas o ensino e a aprendizagem de japonês, a compreensão e expressão oral em língua japonesa e citações e outros aspectos do texto japonês são eixos que podem igualmente ser explorados com a instituição de diálogo com a produção acadêmica do Japão. Tanto os componentes do corpus deste trabalho como as fontes aqui transcritas podem ser empregados com esse fim.

Os temas reunidos ainda conduzem à constatação de que o campo da pesquisa de língua japonesa acadêmica tem sido oxigenado pelo aprendizado de japonês por estudantes estrangeiros (rŷ̂gakusei). Países que têm o ensino de japonês como língua estrangeira estabelecido apresentam, então, condições favoráveis para se tornarem polos produtores de conhecimento do campo. Quanto ao Brasil, entretanto, aparentemente falta uma maior inserção do japonês acadêmico nos cursos da língua oferecidos no país, a fim de que haja insumos para pesquisa a partir de experiências de ensino. 
A propósito, a ênfase constatada sobre a redação em japonês nos textos analisados parece natural se ponderada a importância dos aprendizes estrangeiros para a área. Entre as quatro habilidades de uso da língua, ou seja, fala, compreensão oral, leitura e escrita, a última certamente é mais determinante para o êxito de estudantes estrangeiros no Japão, uma vez que o trabalho escrito, em suas diversas formas, consiste em recurso de avaliação capital nas instituições de ensino japonesas. Desse modo, a maior recorrência de estudos relacionados à redação aparentemente vai ao encontro de uma demanda de ensino proeminente: formar escritores estrangeiros de língua japonesa acadêmica.

Os percursos investigativos reunidos na seção anterior também revelam alternativas para desenvolver frentes de pesquisa acerca do japonês acadêmico. Embora se trate de trajetos variados, observou-se de um modo geral a busca por dois atributos nos estudos examinados. O primeiro é o da reprodutibilidade, que caracteriza áreas de produção de conhecimento científico e consiste em item usual nas recomendações feitas para a redação de trabalhos científicos, como se observa nos textos de Rey (1993, p. 211), Abrahamsohn (2004, p. 31) e Suwa (2005, p. 84-87) e nas normas do International Committee of Medical Journal Editors (2010, p. 13). Os experimentos são fartamente documentados por instrumentos de áudio e vídeo, notas de campo etc. Os relatos acerca das entrevistas, aplicações de questionários, análises textuais são minuciosos. Encontram-se materiais suplementares anexos aos textos, como questionários e planejamento de aulas. Tudo isso contribui para que os estudos forneçam elementos (a princípio) suficientes para sua reprodução, o que os aproxima de áreas científicas.

O segundo atributo é a consistência metodológica. Técnicas estatísticas, softwares especializados, citações de pesquisas similares são comuns nos textos analisados e lhes conferem consistência. Aparentemente há não só a preocupação de expor resultados e conclusões, mas a preocupação de expor resultados e conclusões que permitam generalizar em algum grau e que transmitam credibilidade ao leitor.

Apesar de se tratar de campo de pesquisa incipiente, parece possível afirmar, pois, que os estudos da língua japonesa acadêmica estão assumindo a configuração de um domínio objetivo, experimental, científico.

Os aportes teóricos identificados e suas fontes, por sua vez, podem servir como ponto de partida para pesquisas acerca da língua japonesa acadêmica. Letras, psicologia, educação e ciências sociais aparentemente são as principais áreas de que provêm os aportes. As fontes constituem um conjunto heterogêneo, mas composto sobretudo por matéria escrita em língua japonesa, inclusive textos que apresentam teorias e métodos do exterior e traduções para o japonês de trabalhos estrangeiros.

A presença de um conceito, ideia, modelo norteador ou basilar, contudo, não é indispensável nos estudos de língua japonesa acadêmica, como mostram alguns resultados deste trabalho. Indispensável é revisar tudo o que foi produzido até o momento sobre o assunto escolhido - daí o fato de que inúmeros textos analisados contêm uma seção chamada Pesquisas Passadas (Senkô Kenkyû), mas praticamente não se encontra nos documentos seção que compreenda em seu título a palavra teoria (riron). $\mathrm{O}$ aporte 
teórico é prescindível, o que faz da pesquisa de língua japonesa acadêmica um domínio diferente de muitos daqueles que envolvem o exame da língua e da linguagem em suas várias formas no Brasil, em que uma abordagem, corrente, filiação teórica é condição para que um estudo seja aceito.

Finalmente, no que diz respeito aos referenciais metodológicos e a suas fontes, cabe apontar apenas que seu emprego nos textos flui no sentido da já citada busca por consistência. Podem ser usados, portanto, como chaves para o ingresso no domínio da pesquisa de língua japonesa acadêmica.

\section{Referências dos Textos Examinados ${ }^{10}$}

EYA, Yôko. 'Bunmyakuka' ni motozuku chû/jôkyû bunkei gakushû no wakugumi shian. Akademikku Japanîzu Jânaru, v. 3, p. 99-107, 2011.

IJÛIN, Ikuko. Ikenbun ni okeru jôho kôzô no kinô to ichi: 'Tashika ni' o tegakari ni. Akademikku Japanîzu Jânaru, v. 2, p. 101-110, 2010.

ISHIGE, Junko. Dai ni gengo no sakubun ni taisuru gakushûsha no ishiki. Akademikku Japanîzu Jânaru, v. 1, p. 17-24, 2009.

. 'Dai ni gengo sakubun no purosesu moderu kôchiku' Pairotto chôsa hôkoku. Akademikku Japanîzu Jânaru, v. 2, p. 84-89, 2010.

. Eigo mata wa kankokugo o bogo to suru shokyû nihongo gakushûsha no sakubun katei: Bogo shiyô no kanten kara. Akademikku Japanîzu Jânaru, v. 3, p. 1-8, 2011.

. Chûgokugo o bogo to suru nihongo gakushûsha no nihongo sakubun katei de no chûgokugo shiyô. Akademikku Japanîzu Jânaru, v. 5, p. 29-37, 2013.

KADOKURA, Masami. Nihon ryûgaku shiken no purofishenshî: 'Fukutekisutosei' to iu kanten no teian. Akademikku Japanîzu Jânaru, v. 1, p. 1-16, 2009.

KAGEYAMA, Yôko. Raitingu wâkushoppu no himitsu: Sentaku riron o tôshite raitingu wâkushoppu o nagametemiru. Akademikku Japanîzu Jânaru, v. 3, p. 108-117, 2011.

KAMIMURA, Hatsumi. Daigakuin de no senmon nihongo kyôiku ni kyôdô gakushû o mochiiru igi ni tsuite no ichikôsatsu: 'Jibun ga wakaranai tokoro wa nani ka' ni kizuku jugyô dezain no shiten kara. Akademikku Japanîzu Jânaru, v. 4, p. 1-10, 2012.

KOYAMA, Takayuki. Ikenbun ni okeru mondai teiki no shidô. Akademikku Japanîzu Jânaru, v. 5, p. 64-72, 2013.

NAKAYAMA, Akiko. Gakubu ryûgakusei taishô no nihongo kyôiku o kangaeru: Chûgokujin danshi gakusei no raifu sutôrî o tôshite. Akademikku Japanîzu

10. Todos os textos desta lista estão disponíveis no site do Akademikku Japanîzu Jânaru (AKADEMIKKU JAPANÎZU GURÛPU, 2014a). 
Jânaru, v. 3, p. 78-85, 2011.

NISHINA, Hiromi. Rikôkei hakushi kôki katei no gakusei wa kôtô happyô o dono yô ni toraeteiru ka: Ryûgakusei to nihonjin gakusei e no gurûpu intabyû kara. Akademikku Japanîzu Jânaru, v. 5, p. 38-45, 2013.

NITSÛ, Nobuko. Ronbun no in'yô ni kansuru kisoteki chôsa to in’yô moderu no shian. Akademikku Japanîzu Jânaru, v. 1, p. 65-74, 2009.

OGASA, Emiko. Higaigo no ryûgaku keizoku no handan yôin: Tanki ryûgakusei no baai. Akademikku Japanîzu Jânaru, v. 4, p. 43-50, 2012.

OGAWA, Miyako. Gaikokujin ryûgakusei no kôgi rikai ni tsuite no jiko hyôka: Nihonjin daigakusei to no hikaku o tôshite. Akademikku Japanîzu Jânaru, v. 2, p. 86-98, 2011.

ÔTA, Yûko et al. Raitingu sentâ ni okeru shinjin chûtâ no kadai: Shinjin kenshû wâkushîto no naiyô bunseki. Akademikku Japanîzu Jânaru, v. 5, p. 1-10, 2013.

SAIKI, Yukari; NAKAMURA, Fusako; OGASA, Emiko. Jiko hyôka katsudô de gakushûsha wa kawaru no ka? Chûkyû kaiwa jugyô no jiko hyôka katsudô ga pafômansu ni ataeru eikyô. Akademikku Japanîzu Jânaru, v. 4, p. 51-58, 2012.

SEOMA, Saki. Kaigai no kôtô kyôiku ni okeru akademikku japanîzu to wa: Taiwan no gakushûsha e no intabyû o tôshite. Akademikku Japanîzu Jânaru, v. 5, p. 55-63, 2013.

SHIZUMA, Masako. '-Wa-teiru' in'yôbun no ronbunchû de no shiyô mokuteki. Akademikku Japanîzu Jânaru, v. 2, p. 90-100, 2010.

SON, Aii. Gakushû sutoratejî ga higenba shijiyôhô no shûtoku ni ataeru eikyô ni tsuite: Dai ni gengo gakushûsha to gaikokugo gakushûsha no hikaku. Akademikku Japanîzu Jânaru, v. 2, p. 1-10, 2010.

SUMI, Tomoyuki. Gakujutsu kihon yôgoshû sakusei no kokoromi. Akademikku Japanîzu Jânaru, v. 2, p. 11-21, 2010.

TAKAHASHI, Kaoru. Gakubusei o taishô to shita jitsuyôbun sakusei shidô no kokoromi. Akademikku Japanîzu Jânaru, v. 3, p. 118-126, 2011.

TAKAHASHI, Keiko; IGUSA, Masako. Kyôka gakushû ni tsunagaru nihongo wâkushîto sakusei no kokoromi: Gaikoku ni tsunagaru kôkôsei no shien kara. Akademikku Japanîzu Jânaru, v. 2, p. 111-118, 2010.

TANAKA, Nobuyuki. Jiritsuteki na kakite o ikusei suru katsudô toshite no pia resuponsu: Gakushûsha no pia resuponsu e no tekiô katei no bunseki o tôshite. Akademikku Japanîzu Jânaru, v. 1, p. 25-36, 2009.

. Pia resuponsu ga suikô sakubun ni oyobosu eikyô: Bunseki hôhô to fîdobakku no kyôji ni chûmoku shite. Akademikku Japanîzu Jânaru, v. 3, p. 9-20, 2011. 
YAMAMOTO, Fumiko. Meikai de ronriteki na danwa ni mirareru gutaika/chûshôka sôsa: Edgar DALE no 'keiken no ensui' no ronriteki ninchi purosesu o megutte. Akademikku Japanîzu Jânaru, v. 3, p. 67-77, 2011.

YÔ, Shûga. Akademikku raitingu ni taisuru nihongo gakushûsha no imizuke: Sotsugyô ronbun o sakusei shita chûgoku no daigaku ni okeru nihongo senkôsei e no chôsa kara. Akademikku Japanîzu Jânaru, v. 5, p. 46-54, 2013.

YOSHIDA, Midori. Ikenbun sanshutsu katei no hôryaku no bunseki: Sakubun hyôka ga takai gakushûsha to hikui gakushûsha no hikaku. Akademikku Japanîzu Jânaru, v. 3, p. 21-32, 2011.

\section{Referências}

ABRAHAMSOHN, Paulo. Redação científica. Rio de Janeiro: Guanabara Koogan, 2004.

AKADEMIKKU JAPANÎZU GURÛPU. Akademikku Japanîzu Jânaru. Disponível em: <http://academicjapanese.jp/ajj.html\#list02>. Acesso em: 1 ago. 2014a.

. “Akademikku Japanîzu Jânaru” Tôkôkitei. Disponível em: <http:// academicjapanese.jp/d1/ajj/toukoukitei.pdf>. Acesso em: 1 ago. 2014 b.

BERTERO, Carlos Osmar; KEINERT, Tania Margarete Mezzomo. A evolução da análise organizacional no Brasil (1961-93). Revista de Administração de Empresas, São Paulo, v. 34, n. 3, p. 81-90, mai./jun. 1994.

BORBA, Marcelo Leandro de; HOELTGEBAUM, Marianne; SILVEIRA, Amélia. A produção científica em empreendedorismo: Análise do Academy of Management Meeting: 1954-2005. Revista Administração Mackenzie, São Paulo, v. 12, n. 2, p. 169-206, mar./abr. 2011.

DAVEL, Eduardo; ALCADIPANI, Rafael. Estudos críticos em administração: A produção científica brasileira nos anos 1990. Revista de Administração de Empresas, São Paulo, v. 43, n. 4, p. 72-85, out./dez. 2003.

HOKKAIDÔ DAIGAKU. Syllabus. Disponível em: <http://syllabus01.academic. hokudai.ac. jp/Syllabus/App/Search/SearchMain.aspx>. Acesso em: 2 set. 2014.

HOKKAIDÔ DAIGAKU RYÛGAKUSEI SENTÂ. Kôsu puroguramu. Disponível em: $\quad<$ http://www.isc.hokudai.ac.jp/www_ISC/cms/ cgi-bin/index.pl?page $=$ contents\&view category $=101 \&$ allmenuopen $=>$. Acesso em: 2 set. 2014.

HORII, Keiko. Akademikku Japanîzu Gurûpu (AJG) wa nani o mezashi, nani o tsumikasaneru koto ga dekita no ka: Ima made no kai no katsudô o furikaette. Akademikku Japanîzu Jânaru, v. 1, p. 75-86, 2009. Disponível em: <http:// 
academicjapanese.jp/d1/ajj/75-86-horii.pdf > . Acesso em: 31 dez. 2014.

INTERNATIONAL COMMITTEE OF MEDICAL JOURNAL EDITORS. Uniform Requirements for Manuscripts Submitted to Biomedical Journals: Writing and Editing for Biomedical Publication. [Vancouver], Apr. 2010. 17 p. Disponível em: <http://www.icmje.org/urm_full.pdf>. Acesso em: 30 set. 2011.

JAPAN STUDENT SERVICES ORGANIZATION. Nihon ryûgaku shiken: Nihon ryûgaku shiken jukenshasû no suii]. Disponível em: <http://www.jasso.go.jp/eju/ examinees.html>. Acesso em: 10 jul. 2014.

REY, Luís. Planejar e redigir trabalhos científicos. 2. ed. São Paulo: Edgard Blücher, 1993.

SUWA, Kunio. Ronbun o kaitemiyô! Tokyô: Kokuseidô, 2005.

VIEIRA, Francisco Giovanni David. Narciso sem espelho: A publicação brasileira de marketing. Revista de Administração de Empresas, São Paulo, v. 43, n. 1, p. 8190, jan./fev./mar. 2003. 